\title{
All-for-One Tourism: The Transformation and Upgrading Direction of Regional Tourism Industry
}

\author{
Xiaoxu Feng \\ School of Economics and Resource Management, Beijing Normal University \\ Post Buliding, No.19 Xin-jie-kou-wai Street, Haidian District, 100875, Beijing, China \\ fxxfeng@163.com
}

\begin{abstract}
All-for-One Tourism is a new planning concept proposed by Chinese tourism management practitioners. Based on the present situation of tourism industry development, the new planning concept is to guide the transformation and upgrading of tourist destinations. The development level of all-for-one tourism represents the maturity of regional tourism industry. China has been actively promoting the all-for-one tourism work since 2016. In the process of promoting transformation from scenic spots to all-for-one tourism, we need to grasp development law, strengthen problem-oriented principle and consider comprehensive impacts.
\end{abstract}

\section{Indexing terms/Keywords}

All-for-one tourism; Industrial upgrading

\section{Academic Discipline And Sub-Disciplines}

\section{Economics}

\section{SUBJECT CLASSIFICATION}

\author{
Regional Economics; Tourism Economics
}

\section{TYPE (METHOD/APPROACH)}

\section{Literature Analysis, Comparative Analysis}

Li Jinzao, the Director of China National Tourism Administration, delivered the Work Report "Transform from scenic spot tourism to all-for-one tourism and work persistently towards a new tourism landscape of China's 13th Five Year Plan" in the National Tourism Work Conference in 2016. He proposed all-for-one tourism as the tourism development strategy in the new era to achieve the brand new transformation from scenic spot tourism to all-for-one tourism model. In 2016, the National Tourism Administration launched a nationwide "National all-for-one tourism demonstration area" project and announced two batches of list involved in the creation of " National all-for-one tourism demonstration area". All parts of the country responded actively to fight for the opportunity to create Demonstration area and issued a lot of local documents about the implementation of all-for-one tourism.

\section{The Proposition Background of the All-for-One Tourism}

After nearly 40 years of reform and opening up, the development of tourism in China is mainly to build attractions, scenic spots, restaurants and hotels. This development mode is actually a "scenic spot tourism" model. However, according to the statistics provided by China National Tourism Administration, in 2015, the domestic tourists has reached 4 billion people. As for traveling modes, domestic non-agency organization tourism is more than 95\% and the annual comprehensive contribution of tourism industry is 7.34 trillion, which accounts $10.8 \%$ of the total GDP. 79.11 million people obtained employments directly or indirectly from tourism industry, accounting for $10.2 \%$ of the total employmentpopulation. It can be said that China has entered a new era of mass tourism and independent travel. Tourism has played a more and more obvious role in national economic development. For example, Jiangsu, Zhejiang and other developed areas, the number of tourists in non-scenic spots accounts for more than $65 \%$. The traditional tourism at scenic spots has been unable to meet the needs of modern tourism development. Therefore, how to adapt to the trend of new change and promote transformation and upgrading of tourism is the problem that tourism theory researchers and practitioners have been thinking about. It is also in this context that the all-for-one tourism has become the research hot spot in last two years. The reality requires us to reposition tourism development strategy and change scenic spot tourism to the all-for-one tourism mode.

In scenic spot tourism mode, the construction and operation of closed scenic spots are fragmented and isolated from society, some even conflict. The all-for-one tourism is to change two huge different patterns between the inside and outside scenic spots. This mode of tourism is to take the whole area as a tourist destination with complete function to build and operate so as to achieve the integration of inside and outside scenic spots. The aim is to make everyone become a tourist image and everywhere the tourist environment. For example, we need to consider the unity between styles of new houses built by residents and the overall landscape; to pay more attention to the needs of local residents in the tourism development process; to take tourism needs into account in the water conservancy construction besides other functions such as flood control, drainage improvement and drought resistance. 


\section{The Connotation Analyses of All-for-One Tourism}

All-for-one tourism was first mentioned in the tourism planning concept of Chengdu, Dalian and other places. Local tourism practitioners have made meaningful explorations. Li Xinjian et al (2013) argued that "all-for-one tourism" refers to " the active integration of various industries, the concerted efforts of various departments, the participation of the whole city residents and the full use of all the destination attractions to provide the coming tourists with experimental products which can fully meet their demand for experience." He also summed up the "four new" (resources, products, industries and markets) and "eight all"(all elements, all professions, all process, all sides, all time and space, all society, all departments and all tourists). Tang Shaozhong (2014) put forward the "Yu Zhong model" of all-for-one development, that is, the "four whole" mode (the whole landscape, the whole time, the whole industry and the whole people), which is most applied in the tourism planning industry. Li Jinzao (2016), the Chinese National Tourism Administration Director, pointed out that "The all-for-one tourism is a new regional coordinated development mode by using tourism to promote coordinated development of economy and society. It regards tourism as the dominant industry in a certain area. It can achieve regional conformity of organic resources, industrial integration and development as well as social co-construction and share through systematic optimization and upgrading of regional economic and social resources in the area, especially tourism resources, related industries, ecological environment, public services, institutional mechanisms, policies and regulations and the quality of civilization. " He also put forward nine transformations, five distinct characteristics and four basic standards. Based on this, Shi Peihua (2016) summarized the "five integration", including tourism landscape, service support, tourism management, industry linkage and result sharing. Yang Zhenzhi (2016) specifically mentioned the rich areas of tourism resources in the discussion of all-for-one tourism. He stressed that tourism function area is the high-level development model. Zhang Hui et al. (2016) pointed out all-for-one tourism should not be over-interpreted from the perspective of "all", but should be focused on the angle of "domain", including "space domain, industry domain, element domain and management domain". China National Tourism Administration (2016) defined all-for-one tourism in the announcement of the first list of "national all-for-one tourism demonstration zones". The basic concept is as follows: "Allfor-one tourism is to take a specific area as a complete tourism destination for overall planning, comprehensive management and integrated marketing and promotion. It is an advanced model to promote the whole region, factor and industry chain development and to achieve the comprehensive tourism construction, communion and sharing.

The five characteristics of tourist destination summarized by Chris Cooper et al. (2004) provide an analytical perspective for us to view the necessity of all-for-one tourism development.

First, comprehensive tourism destinations include basic elements, including attraction, equipment (accommodation, catering, retail and other service facilities), accessibility and ancillary services and so on. All-for-one tourism development focuses on the core attractions to further extend and enrich other basic contents including both hardware and software.

Second, tourist destination is a set containing rich connotations, which requires all components including the service quality should be uniform, since non-uniformity will affect the image of tourist destination and reduce its attractiveness. The problem of " huge difference between the inside and outside of scenic spot" has been very prominent in the development of China's tourism destination, which can be exactly solved by the all-for-one tourism mode.

Third, tourist destination is the cultural wealth. Chris Cooper emphasized its cultural attributes and thought this directly affects the tourists' choices of consumer behavior. Apart from the development and allocation of basic tourism elements, the all-for-one tourism also focuses on cultural construction of tourism destinations and helps to enhance its cultural attraction.

Fourth, tourist destination, like other service products, also has the quality of non-storage and indivisibility, which can only be experienced by tourists themselves. All-for-one tourism development attaches importance to tourists' experience effect and concerns about the diversified needs of tourists, which helps to maintain and enhance both image and reputation of the destination.

Fifth, besides tourists, the users of tourist destination also include local residents and employees. Today's tourists experience needs have been growing diversified. More tourists hope that the process of tourism can be integrated into local life to meet diversity of experience needs of different cultures. Therefore, the life of local residents has also become a tourist attraction. The development of tourist destination will face the problems of the relationship between different interest groups. Since all-for-one tourism development is conducive to enlarge the contribution of tourism industry, the winwin situation among tourism destination stakeholders is a necessary condition for the success of all-for-one tourism development.

Li Jinzao (2016), China National Tourism Administration Director, proposed the nine kinds of transformation from the scenic spot tourist model to the all-for-one tourism: First, the overall development and change from a single scenic spot to the comprehensive construction and management; second, the change from ticket economy to industrial economy; third, the change from the closed management system that the tour guides must be appointed by the travel agency to the open management that tour guides exchange orderly and freely; fourth, the change from extensive and inefficient tourism to fine and efficient tourism; fifth, the change from the closed travel self-circulation to the open integrated development mode; sixth, the change from self-industry construction to the whole society building and sharing; seventh, the change from the security administration within the walls of scenic spots to the legal comprehensive management; eighth, the change from departmental behavior to the comprehensive industries administration; ninth, the change from the narrow international cooperation that international tourists are only received by scenic spots to the all-round, multi-level international exchanges and cooperation. 
This thesis believes that in the nearly forty years of China's reform and opening up, tourism industry started from scratch and experienced the rapid development process from small to large. From the initial major tourist attraction to the mature famous scenic spots, then to the rich and comprehensive tourist resort, all of these has followed the life cycle principle of tourist destination. Therefore, the all-for-one tourism is the new planning concept that China's tourism management practitioners put forward to guide the transformation and upgrading of tourism industry based on the present condition of tourism development which represents the new direction of modern tourism development. The level of all-for-one tourism development represents the maturity of regional tourism industry.

\section{Two key perspectives to promote all-for-one tourism}

At present, China is actively promoting the development of all-for-one tourism and accelerating the transformation and upgrading. In the process of promoting the transition from scenic spots to comprehensive tourism, the principle of industrial development and regional development concept are worth attention.

\subsection{Grasp the development law and strengthen the problem-oriented thinking}

The traditional scenic spots tourism development model has been unable to adapt to the new industrial development needs, which requires us to compare the all-for-one tourism development model and the traditional one, as shown in the following table. We need to strengthen the problem-oriented thought and upgrade the industry transformation to adapt to new trends.

Table 1 Comparison between traditional tourism development model and all-for-one tourism development model

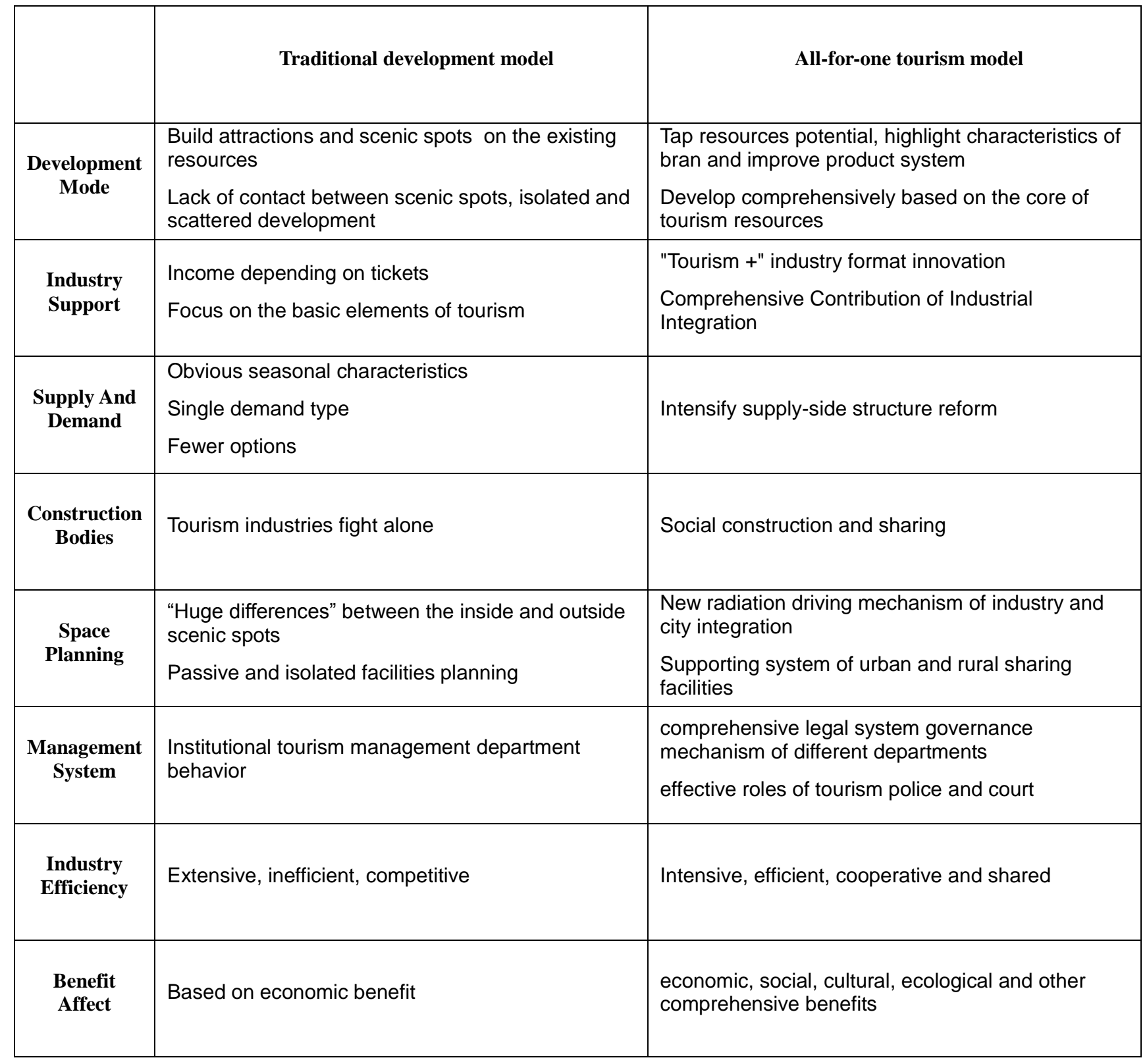


At present, most of the China's tourist destinations have gone through the "exploration period" and "participation period". They made good achievements in the tourism industry, while at the same time, there have been specific problems in the "development" and "curing" periods. In the 18 variables related to the tourist destinations development life cycle summarized by Weaver. D. and Oppermann. M. (2000), many aspects including the space pattern, attractiveness, seasonal influence, length of stay, commercialization degree, relationship with local residents, environment stress, started to have problems in the "development" and "curing" periods. This phenomenon has appeared in China's tourism destination development process. For example, the product structure in some traditional well-known tourist destination is single, visitors' stay time is short, the ticket economy has not been improved for many years, and residents' attitude to tourism industry development is "indifferent". These are the issues need to be solved urgently in the all-for-one tourism development now.

Therefore, how to grasp the development law, find problems in the contrast and seek innovation should be the important contents that all-for-one tourism consider about. We need to put an end to the " old wine with new bottle " phenomenon and simply plus the word "all-for-one". (Liu Jiaming, 2016). Problem-orientation should become the guiding method to practice the all-for-one tourism.

\subsection{Combine all-for-one tourism with regional development and consider integrated impact}

All-for-one tourism emphasizes regional comprehensive development concept guided by tourism industry. In order to understand the all-for-one tourism, we need to combine it with the regional development. Apart from attaching importance on the development of tourism industry itself, we need to look outside the box and pay attention to analyze the comprehensive influence of tourism industry to the regional development.

In order to promote the development of all-for-one tourism, we ought to promote green development, to truly enlarge the green properties of tourism industry, to bring the positive role of tourism industry into full play, and to improve the green efficiency of regional economy through forced mechanism, linkage mechanism, radiation mechanism and sharing mechanism. It is also necessary to pay attention to the social and cultural impact of the tourism industry on the area, to promote the exchange and understanding of different cultures, to protect and inherit the traditional cultural heritage, to improve people's leisure level and life quality and eliminate the negative impact brought by tourism development on the tourism destinations as far as possible.

In order to promote the development of all-for-one tourism, we also need to attach importance to the impact of tourism on the coordinated development of urban and rural areas. In areas of enriched tourism resources, the new urbanization guided by tourism has been practiced. However, in the process of tourism blended into the traditional rural and agricultural development, the problems and shortcomings still exist, such as the guarantee of the interests of farmers after the issue of excessive capitalization, semi-urbanization problems, should all become the key issues that all-for-one tourism should take seriously.

\section{The measurement and evaluation of all-for-one tourism development level}

A prominent problem in developing all-for-one tourism is how to evaluate the effect of a region's tourism development. Shi Peihua (2016) has made a specific evaluation on the all-for-one tourism demonstration areas from the following six major aspects: (1) with distinctive features, strong attractiveness and rich product formats; (2) with perfect infrastructure and public services; (3) with outstanding advantages, prominent position and comprehensive function; (4) should highlight tourism reform and innovation and attach great importance to development and effective security measures; (5) should be safe, civilized and orderly; to make both tourists and local residents satisfied; (6) ecological environment and landscape should be well protected and cultural heritage should be cherished and carried forward. The six features are summarized comprehensively, with both the qualitative and quantitative indicators. The People website monitoring center (2016) evaluated the core influence of the all-for-one tourism demonstration areas from the perspective of public opinions. There are six dimensions: media transmission degree, A-level scenic areas, traffic convenience, excellent environmental index, direct contribution to tourism, and tourism additional value. Chinese Academy of Social Sciences Public Opinion Laboratory (2016) also released the "National Development Index of the All-for-one Tourism". Six assessment indicators has been put forward to declare the "National All-fr-oneTourism Demonstration Zone" developed by the International Tourism Administration. These indicators are mainly to highlight the economic function of tourism. The regions meeting the declaration conditions mostly are the areas with better tourism development. In the two batches of list published in 2016, most of the regions are the places with rich tourism resources. This aims to highlight the demonstration function, but there should be more indicators in the real process of creation.

As a new development concept and model of tourism industry, the all-for-one tourism represents the direction of tourism transformation and upgrading. Therefore, the level of all-for-one tourism development in a certain area represents the level of regional tourism industry transformation and upgrading. Based on this, this paper proposes the concept of all-for-one tourism development index, which aims to define the level of regional tourism industry transformation and upgrading and the maturity of tourism industry.

What need to be emphasized is that the promotion of all-for-one tourism is not to build scenic spots, restaurants, hotels or develop tourism industry in everywhere. Emphasizing the all-for-one tourism development index in one region is not to measure its development intensity in space. These misunderstandings should be avoided.

According to the administrative division, the present all-for-one tourism can be divided into three levels: provincial-level, city-level, regional and district-level. Hainan province was identified as the country's first all-for-one tourism demonstration province in the China National Tourism Work Conference in 2016. The two batches of the list of "National tourism 
demonstration area" include both prefecture-level cities and counties. It is worth noting that the cross-administrative tourism destinations still exist based on the analysis of regional tourism resources integration and completeness of tourism resources, which can better optimize regional resource allocation and avoid vicious competition.

The provincial tourism development indexes can represent maturity of the province's tourism industry and its transformation and upgrading level. The higher index shows a more mature tourism industry, a higher level of tourism industry transformation and upgrading, and a higher level of industrial modernization. Similarly, there are also the city or district-level all-for-one tourism development indexes.

Premier Li Keqiang reaffirmed the guiding ideology of tourism development in Guo Fa Papers [2009] with No. 41 at the opening ceremony of the first World Tourism Development Conference in 2016. In his speech, he pointed out Chinese government attached great importance to the status and role of tourism, and introduced a series of laws, regulations, policies and measures to promote the reform and development of tourism. The purpose is to make the tourism industry into a strategic pillar industry of national economy and a modern service industry with mass satisfaction. Therefore, we can build of all-for-one tourism index evaluation system from the two levels of comprehensive contribution and satisfaction based on the analysis of both all-for-one tourism and regional tourism development.

All-for-one tourism is a comprehensive and highly-recapitulative concept, which can be evaluated and analyzed from many other perspectives and dimensions. In general, in order to reflect development connotation of all-for-one tourism objectively in a more comprehensive way, it is better to choose rich indexes and combine both qualitative and quantitative data in specific work. At present, China National Tourism Administration is actively promoting tourism statistics and data construction work. With the continuous improvement of tourism-related statistical data system, especially the continuous application of large data technology, it is reasonable to believe that the all-for-one tourism evaluation index system will be more plentiful and the evaluation will be increasingly objective and comprehensive.

\section{REFERENCES}

1. Li Jinzao. The All-for-one tourism is promising. China National Tourism Administration website. http://www.cnta.gov.cn/zdgz/qyly/201602/t20160207_760080.shtml

2. Li Xinjian, Zhang Lingyun, Cui Li. All-for-one tourism: The innovated concept of building a world-class tourist destination - taking Beijing as an example [J]. Human Geography, 2013 (3): 130-134.

3. Tang Shaozhong. "All-for-one tourism" driving factors and development model. China Travel News, June 4, 2014, No. 014 version.

4. Shi Peihua. The series interpretations of all-for-one tourism. China National Tourism Administration website. http://www.cnta.gov.cn/ztwz/zghy/rdjj/201602/t20160204_759828.shtml

5. Yang Zhenzhi. The connotation and development stage of all-for-one tourism [J]. Journal of Tourism, 2016,31 (12): 01-03.

6. Zhang Hui, Yue Yanxiang. The rational thinking about all-for-one tourism [J]. Tourism Journal, 2016,31 (09): 1517.

7. Chris Cooper, John Fletcher, David Gilbert, Stephen Wanhill, Rebecca Shepherd. Principles and Practice of Tourism [M]. Beijing: Higher Education Press, 2004.

8. Weaver, D .and Oppermann, M. (2000). Tourism Management. Milton, Australia: John Wisley \& Sons Australia, Ltd., p.319.

9. Liu Jiaming. The background, misunderstanding and starting point of all-for-one tourism creation. [J]. Tourism Journal, 2016,31 (12): 07-09.

10. $\mathrm{Li}$ Keqiang. Let tourism become the boat of world peace and development. Xinhua: http: //news.xinhuanet.com/ttgg/2016-05/20/c_1118898593.html

\section{Author' biography}

Xiaoxu Feng. The PhD candidate in School of Economic and Resource Management at Beijing Normal University. The filed of education is green economics, and research area is regional tourism economic development and tourism planning.

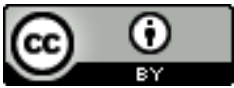

This work is licensed under a Creative Commons Attribution 4.0 International License.

DOI:10.24297/jssr.v11i2.6144 